Article

\title{
Buildings Energy Performance in a Market Comparison Approach
}

\author{
Manuela De Ruggiero ${ }^{1}$, Giuseppina Forestiero ${ }^{1}$, Benedetto Manganelli ${ }^{2}$ and Francesca Salvo ${ }^{1 \text {,* }}$ \\ 1 Department of Environmental and Chemical Engineering, University of Calabria, Via Pietro Bucci Cubo 46b, \\ 87036 Rende, Italy; manueladeruggiero@gmail.com (M.D.R.); forestiero.ing@gmail.com (G.F.) \\ 2 School of Engineering, University of Basilicata, Viale dell'Ateneo Lucano, 85100 Potenza, Italy; \\ benedetto.manganelli@unibas.it \\ * Correspondence: francesca.salvo@unical.it, Tel.: +39-984-496770
}

Academic Editor: Pierfrancesco De Paola

Received: 16 December 2016; Accepted: 15 February 2017; Published: 22 February 2017

\begin{abstract}
The current regulations on the energy certification of buildings represent for the real estate market and the building sector a real cultural revolution. In recent years, the focus on the energy efficiency of buildings has grown exponentially. It is therefore necessary that the property valuations and methodologies used for this purpose bear in mind the energy quality of buildings. This study aims to determine the contribution of an energy performance feature to the real estate property value. This information can help, on the one hand, to understand the energy savings and the corresponding savings income in the property management and, on the other, to control the air pollution from $\mathrm{CO}_{2}$ emission reduction. The energy performance hedonic price and the $\mathrm{CO}_{2}$ emission price are appraised in the Market Comparison Approach (MCA).
\end{abstract}

Keywords: sustainability; energy efficiency; real estate market; hedonic price; value

\section{Introduction}

The relationship between energy efficiency and building production is to be found in the ever increasing importance that this topic has acquired in all productive sectors of most industrialized countries. Energy is a factor of economic growth, welfare, and technological progress as well as social progress. The industrial and social development, which in the last fifty years has undergone significant acceleration and caused rapid and profound changes that have inevitably produced strong tensions in the global energy system, has highlighted the importance of the concept of sustainable development. The question about sustainable development, which is really relevant today, has among its main objectives to guarantee a conscious development of the world energy system without compromising the earth's balance.

The unconstrained growth of global consumption, however, is not the only energy problem; in fact, to make the efficiency issue one of crucial importance in the years ahead, there is also the environmental issue. The production of energy, together with the use of fossil fuels, has serious 'side effects' on the environment, Earth's climate, and human health, which are caused by emissions of harmful pollutants and greenhouse gases, which cause global warming and environmental changes such as melting glaciers and rising sea levels. An important part of such climate change could be avoided through a reduction of the final consumption of heat and electricity, which explains once again the centrality of the issue of energy efficiency.

Energy is at the same time the question and the solution of problems related to the progress of society because, on the one hand, it is essential and irreplaceable component of the development of man's activities and, on the other, is one of the main causes of the negative effects of such activities on environmental and climate stability, both on a local and global scale. 
Concerning building activities, it is crucial to encourage and promote interventions that both allow better energy performance of buildings and respond to a primary environmental need to reduce polluting emissions. A boost in this direction can come from fiscal policy actions that result in the internalization of environmental costs into the value of the buildings, resulting in a loss of the value of real estate that consumes fossil fuels and pollutants and a corresponding revaluation of energy-efficient buildings.

The promotion of sustainable development thus has a direct impact on the housing market. If in the past, in fact, the real estate market was characterized by a purely quantitative question, today the same is characterized by a substantially qualitative demand. The concept of the quality of building manufacturing concerns very closely the issue of energy performance. The latter can be considered a proxy of several real estate characteristics, related in some measure to the constructive and technological features.

To address the climate problem created by the greenhouse effect and to promote energy efficiency, the European legislator with Directive/91/EC, 2002, on the energy performance of buildings set the laws, regulations, and administrative provisions designed to comply with the new obligations to reduce energy consumption and to make transparent to the energy operators' performance in the property market through energy certification. It constitutes a potential tool of transformation for the real estate market by providing objective information on the energy performance of the property to be acquired or to be rented. The mandatory certification should then generate a positive effect on the market value of properties that have good performance in the medium term and promote the upgrading of low-energy performance buildings. This study's issue is to determine the hedonic contribution of energy performance to the property value from a quantitative point of view. The objective is pursued through an economic analysis of the main detectors of the energy performance of a building, which are found in most of the energy certificates of European countries, thus making possible the international implementation of repeatable proposed estimation methodology. The energy certificate should be an important comparison document between different properties under the same conditions from the very first stages of market research. The proposed methodology makes reference to the Market Comparison Approach (MCA) by identifying an exogenous determination math mode of the hedonic price related to the energy performance and carbon dioxide $\left(\mathrm{CO}_{2}\right)$ features. In this way, it is possible to quantify the increase or decrease of property values linked to the energy performance and carbon dioxide $\left(\mathrm{CO}_{2}\right)$ components.

\section{Literature Review}

In an era of environmental awareness and concerted action toward sustainable energy management, energy efficiency is a key challenge. Buildings account for $40 \%$ of the energy consumption in Europe [1], and residential homes contribute to around one sixth of emissions globally [2]. Supplementary literature has begun to emerge on the willingness to pay for energy efficiency [3-10], whether energy savings are considered in buying decisions [11,12], and if financing should stem from private or public sources [13-16].

The majority of empirical evidence on the impact of energy certificates on building prices supports the assumption that people are willing to pay extra for more efficient properties in both the commercial and residential sectors. Studies in the commercial sector, primarily in the United States, suggest that green offices acquire a price premium from $13 \%$ to 30\% [17-22]. Similarly, positive results of a lower magnitude are observed in the residential sector. Studies on the influence of an energy certificate on the value of properties were conducted in Netherlands and in Ireland [9].

A wider study undertaken by the European Commission [8] compares residential premiums associated with Energy Performance Certificates (EPCs) in five European countries; Austria, Belgium, France, Ireland, and the UK. The sales price effects from increased energy efficiency are significant and positive in all cases apart from Oxford in the UK. 
Further studies in Europe, Australia, the United States, and Singapore confirm findings that residential buyers are willing to pay a premium for energy efficient housing [5-7,23-28], although some papers have produced more mixed results $[11,12,29,30]$.

To ascertain the extent of the impact of energy efficient investments on the existing building stock, there has been a growing focus on measuring the impact of energy efficiency on the overall value of buildings $[19,31,32]$.

This methodology deploys econometric techniques to identify the impact of building characteristics on value and can thus be used to identify the impact of green investments on building value. Hedonic regression is frequently used in real estate economics to establish consumers' willingness to pay for a given feature ranging from views to trees to clean air to proximity to amenities $[33,34]$. This analytical technique allows appraisers, investors, and policy makers to understand the value of otherwise hard to quantify property features. At its core, the approach compares the price of two buildings deemed otherwise identical apart from the feature in question. In the case of green labels, researchers use data on building rent and value, controlling for building class, size, age, and other relevant features to determine how green labels alone influence the price [35-38]; worker satisfaction [20,39]; and the occupancy rate $[20,39,40]$. Although this method does not necessarily provide insight into the micro-scale decisions that go into appraisal of green label buildings, it does indicate how those decisions culminate in the macro-scale price premiums associated with these labels $[41,42]$.

\section{Policy Background}

The United Nations Framework Convention on Climate Change (UNFCCC), established in 1992, initiated an international framework for negotiating greenhouse gas emissions targets for participating countries in an effort to stabilise global warming. The European Union is among 195 parties that are currently signatories of the Kyoto Protocol, an extension of the UNFCCC, which was signed in December 2012 at Qatar National Convention Centre in Doha, Qatar, and has an internationally binding target to reduce emissions by at least 18\% compared to 1990 levels by 2020 (UNFCCC 2012). International commitment to reducing greenhouse gas emissions was most recently reinforced by an agreement by the G7 (Canada, France, Germany, Italy, Japan, the United Kingdom, and the United States) to decarbonise the global economy by the end of the century [43]. In conjunction with carbon and renewable policies, the European Union's Energy Efficiency Directive (2012/27/EU) aims for a $20 \%$ reduction in energy demand in the European Union as a whole by 2020 [44]. One of the main policy tools for reducing energy consumption in the buildings sector and advancing awareness of the energy performance of buildings are EPCs. EPCs are provided for benchmark ranking for buildings based on their predicted energy consumption per square meter and the associated $\mathrm{CO}_{2}$ emissions. Since the 1990s, a combination of voluntary and mandatory EPC schemes across residential, commercial, and/or public buildings have emerged in countries such as Australia (NatHERS, Green Star), Russia (Energy Passport), the United States (LEED, Energy Star, HERS Index), Japan (CASBEE), and Singapore (Energy Smart, BCA Green Mark). In the European Union, the 2002 EU Directive on the Energy Performance of Buildings (EPBD 2002/91/EC recast 2010) introduced a mandatory requirement for member states to provide specific information on a building's energy performance and recommendations for energy saving measures to prospective purchasers and tenants in property transactions. From 2013 onwards, amongst other things, the recast EPBD ensures that all properties advertised for sale or for rental, excluding certain buildings such as protected structures, include an official energy certificate (The European Parliament the Council of the EU 2010b).

In transposing the Directive 2002/91/EC Energy Performance of Buildings Directive (EPBD), which establishes the obligation of energy certification of buildings, the Member States have launched or are launching national measures requiring the adoption of energy certificates, first for new buildings and only later for existing ones.

Almost all countries have adopted a national methodology that sets the performance requirements for new buildings. For countries with existing regulatory requirements prior to 2002 (for example, 
Czech Republic, Belgium, Estonia, Bulgaria, Hungary, Ireland, and Poland), there was a holistic approach to the entire building. In some cases, performance requirements for individual technical elements were added, ensuring the overall energy efficiency of the building (for example, Denmark). Other countries will adopt alternative methods, to which there are two parallel approaches (for example, Norway, Spain, Poland, and Switzerland).

It is important not to compare the performance requirements established by the Member States, given the variety of the methods of calculation used and the main different definitions (for example primary and final energy, heated floor surface, the carbon conversion factor, energy consumption, total energy requirements, etc.). The setting of the energy performance requirement is generally expressed in $\mathrm{kWh} / \mathrm{m}^{2}$.year, which depending on the value, corresponds to a literal scale from A to $\mathrm{G}$ (for example, in Italy, France, the United Kingdom, etc.). Some countries (for example Belgium and Germany) instead express the performance requirements relating to a score in numbers.

You can earn from all certificates of energy performance three representative indicators of energy efficiency of the building, which are:

- $\quad$ The index of energy performance;

- $\quad$ The energy class;

- $\mathrm{CO}_{2}$ emissions.

These parameters are representative of the energetic quality of the building and therefore can be considered nomenclatures, able to take into account energy efficiency in the appraisal of the most probable market value of a property.

\section{Methods}

The contribution of a building's energy performance feature to price formation is designed according to the Market Oriented approach, one of the three approaches considered in the International Valuation Standards (IVS) [45].

The IVS (International Valuation Standards) define the Market Oriented Approach, the Income Approach, and the Cost Approach as the internationally recognized appraising methods. When the real estate market is active and all necessary market data are available, the Market Comparison Approach (MCA) is the most direct, probative, and documented method used to appraise real estate market values; in particular, the MCA is the most important method referable to the Market Oriented Approach.

The Market Comparison Approach is known by several different names in the appraisal literature. In some of the older literature, it is called the Market Data Approach, while elsewhere it is referred to as the Grid Adjustment Technique [46]. The Market Comparison Approach (MCA) is an assessment procedure that leads to the evaluation of the market value of a property based on a comparison with the prices of similar properties recently purchased or sold. The MCA comes to determine the property value through a complex series of monetary adjustments. The MCA is suitable for the evaluation of any kind of property, from condominiums to agricultural land or buildings with special architectural value, provided that there is an adequate number of recent transactions of similar properties through which you can make the comparison. The MCA is a systematic procedure based on adjustments, corrections in monetary terms, to be made at the market prices of real estate comparables, to take account of the differences between the characteristics of real estate comparables and those of the property to be appraised. The MCA is constituted of the followings steps:

1. market analysis, designed to collect the real estate transaction dates of properties similar to that being valued;

2. choice of the characteristics which will drive the comparison;

3. compilation of the data table and drafting of technical documents (photos, plans, etc.);

4. hedonic price analysis; 
5. sales adjustment grid;

6. reconciliation.

The hedonic price analysis (step 4) is the central phase of the proceedings, hedonic prices being the basic adjustments of the MCA. In particular, for each feature a hedonic price is calculated and used to adjust the observed prices. The evaluation of the hedonic prices makes use of the substitution principle, the complementarity principle, and the evaluation criteria (market value and cost value). The hedonic price can assume positive values when the variation in the increase of the characteristic corresponds to an increase in the price, negative values when a variation in the increase of the characteristic corresponds to a decrease in the price, and null values if a variation of the characteristic does not produce any change in the price.

In the following paragraphs, the appraisal methodology will be illustrated according to the coefficients used to simplify the traditional application of the MCA $[47,48]$. As explained in theory, this has been then applied to a case study.

\subsection{Hedonic Price of Energy Performance Index Feature}

The energy performance index indicates how much energy is consumed so that the building (or building unit) has the required comfort conditions.

The determination of the hedonic price of the energy performance index (EPI) in the MCA was treated as a quantitative feature the same way as the surface characteristics, a level floor, technological systems, etc.

The hedonic price of the energy performance feature can be performed by applying a financial method, namely the Discounted Cash Flow Analysis (DCFA) [49]. The DCFA considers the impact of a series of costs and incomes on the current revenues generated by the characteristic of 'energy performance', from purchase to resale. This means we need to expect during the reference period (availability period) the expected revenue in terms of lower energy consumption and, at the end of the period, the residual value of the same feature.

The hedonic price of Energy Performance Index characteristic $P_{\text {EPI }}$ is calculated by:

$$
P_{\mathrm{EPI}}=\sum_{t=1}^{n} C_{\mathrm{E}} \cdot(1+i)^{-t}+P_{\mathrm{EPI}} \cdot(1+i)^{-n}
$$

where:

- $\quad P_{\mathrm{EPI}}$ is the hedonic price of the characteristic energy performance expressed in $€ / \mathrm{kWh} \mathrm{m}^{2}$.year;

- $\quad C_{E}$ is the variable annual income during the transitional period, coinciding with the annual cost of energy, expressed in $€ / \mathrm{kWh}^{2}$.year;

- $\quad P_{\mathrm{EPI}} \cdot(1+i)^{-n}$, is the value of the characteristic energy performance index at the end of the availability period of the property expressed in $€ / \mathrm{kWh}^{2}$.year.

- $\quad i$ is the capitalization rate;

- $\quad t$ is the generic year of the transitional period expressed in years;

- $\quad n$ is the duration of the investment in the period of possession of the property (years).

Real estate investments have medium and long-term time horizons, and the appraised hedonic price of energy performance index feature at the end of the availability period of the property is for a magnitude far into the future. In addition, the annual energy costs may vary during the period of availability.

In particular, the $C_{\mathrm{E}}$ annual energy cost is assumed to be variable in geometric progression at a constant rate $g$, and the value of the index of energy performance characteristics at the end of the availability period of the property ( $\left.P_{\mathrm{IPE}}\right)$ has appreciated or depreciated gradually at a rate of $d$ for the duration at the rate $n$. 
For $i>g$ :

$$
P_{\mathrm{EPI}}=C_{\mathrm{E}} \cdot \frac{1-\left(\frac{1+g}{1+i}\right)^{n}}{i-g} \cdot \frac{1}{1-\left(\frac{1 \pm d}{1+i}\right)^{n}} .
$$

For $i<g$ :

$$
P_{\mathrm{EPI}}=C_{\mathrm{E}} \cdot \frac{\left(\frac{1+g}{1+i}\right)^{n}-1}{g-i} \cdot \frac{1}{1-\left(\frac{1 \pm d}{1+i}\right)^{n}} .
$$

Assuming that the investment period is comparable to the useful life period of the property, which can be considered unlimited, calculating the limit as $\mathrm{n}$ to tend to infinity $(n \rightarrow \infty)$ with $i>g$, the hedonic price of the energy performance index is expressed as follows:

$$
P_{\mathrm{EPI}}=\frac{C_{\mathrm{E}}}{i-g} .
$$

For $i<g$, the hedonic price is equal to:

$$
P_{\mathrm{EPI}}=\frac{C_{\mathrm{E}}}{g-i} .
$$

\subsection{The Characteristic of the Carbon Dioxide Emissions Value}

A further energy performance indicator is the carbon dioxide emission from buildings. Heating, lighting, air conditioning, ventilation, and refrigeration are the main factors that determine the direct energy and thus carbon emissions. While the energy performance index component directly affects the portfolio of potential buyers and may result in a corresponding increase/decrease of the property value, the component of carbon dioxide emissions is an externality, which is a benefit for the purchaser but not for the community. The latter can be quantified in order to measure the compensation to those who generate it in the form of tax deductions or incentives. The value of the characteristic related to carbon dioxide emissions energy performance has been formulated according to the same methodological approach used to define the hedonic price index of energy performance.

However, in this case, the parameter to be considered in order to quantify the contribution of $\mathrm{CO}_{2}$ to the value is the so-called carbon credits. Carbon markets are strategic tools of economic policy to reduce greenhouse gas emissions responsible for global warming, often used in combination with other policies such as the taxation of greenhouse gases or carbon taxes and regulations governing the use of low production technologies and greenhouse gas consumption. The reduction of greenhouse gas emissions is exchanged in the form of 'carbon credits', usually expressed in units tons of $\mathrm{CO}_{2}$.

2003/87/EC Directive of the European Parliament and of the Council has set up a system for the exchange of greenhouse gas emission allowances in the European Union in order to promote the reduction of polluting emissions (European Union Emissions Trading Scheme-EU ETS) [50]. This is the first concrete implementation in Europe of one of the mechanisms under the Kyoto Protocol to counteract climate change. The average price of a carbon credit (or permit or emission quota), in reference to the prices varied from the year of birth of the market (2003) up to year of research (2015) traded in the carbon market, is established at around $15 € / \mathrm{tCO}_{2}$.

The equation used to quantify the hedonic price of energy performance for $\mathrm{CO}_{2}$ emission then becomes:

- $\quad$ for $i>g$ and $n \rightarrow \infty$ :

$$
P_{\mathrm{CO}_{2}}=\frac{C_{\mathrm{CO}_{2}}}{i-g},
$$


- for $i<g$ and $n \rightarrow \infty$ the hedonic price is expressed as follows:

$$
P_{\mathrm{CO}_{2}}=\frac{C_{\mathrm{CO}_{2}}}{g-i},
$$

where:

- $\quad P_{\mathrm{CO}_{2}}$ is the hedonic price of the characteristic related to $\mathrm{CO}_{2}$ emissions. $\left(€ / \mathrm{m}^{2} \cdot \mathrm{kgCO}_{2}\right.$ year);

- $\quad \mathrm{C}_{\mathrm{CO}_{2}}$ is the annual cost of the building's $\mathrm{CO}_{2}$ emissions calculated according to the average of a carbon credit price $\left(€ / \mathrm{m}^{2} \cdot \mathrm{kgCO}_{2}\right.$ year $)$;

- $\quad i$ is the capitalization rate;

- $\quad i$ is the capitalization rate;

- $\quad g$ is the annual cost of carbon dioxide emissions variation rate.

\section{Case Studies}

In order to test the accuracy of the proposed approach, this case study follows a numerical example based on a concrete appraisal sample concerning flats in condominium located in Cetraro. Cetraro $\left(39^{\circ} 31^{\prime} 3.36^{\prime \prime} \mathrm{N}, 15^{\circ} 56^{\prime} 32.64^{\prime \prime} \mathrm{E}\right)$ is an Italian town of 10,076 inhabitants, located on the Tyrrhenian coast in the Province of Cosenza (coastal/mountain area, elevation from 0 to 1.118 a.s.l) The district presents a surface of $66.14 \mathrm{~km}^{2}$, with a population density of 152.34 inhabitants $/ \mathrm{km}^{2}$. It falls into the $C$ climate zone, with 1.117 degree days. We proceeded to carry out the market analysis, designed to collect data relating to contracts in recent sales of properties similar to the one being valued. In this way, the analysis identifies three trades of properties similar to the one being valued, all located in the same neighbourhood in order to delete the locational component.

For the sample of data chosen to carry out the analysis, we have identified driver characteristics; that is, the features that are common to the entire sample but different in mode. These features are shown in Table 1.

Table 1. Data.

\begin{tabular}{ccccc}
\hline Sale Price and Real Estate Feature & Comparable A & Comparable B & Comparable C & Subject \\
\hline Sale Price (SPR) $€$ & $159,000.00$ & $172,000.00$ & $165,000.00$ & $?$ \\
Surface (SUR) mq & 85.00 & 118.00 & 105.00 & 80.00 \\
Restrooms (RES) No & 2.00 & 1.00 & 1.00 & 2.00 \\
Maintenance (MAI) point & 2.00 & 4.00 & 2.00 & 4.00 \\
Floor level (FLO) level & 4.00 & 6.00 & 5.00 & 3.00 \\
Energy performance index (EPI) $\mathrm{kWh} / \mathrm{m}^{2} \cdot \mathrm{a}$ & 220 & 200 & 218 & 265 \\
Carbon dioxide emission (CDE) $\mathrm{kgCO}_{2} / \mathrm{m}^{2} \cdot \mathrm{a}$ & 54 & 58 & 75 & 65 \\
\hline
\end{tabular}

The most difficult step in the application of the proposed methodology is the analysis of the hedonic prices of real estate features. On the basis of the data table, the hedonic price of each feature is calculated as indicated in Salvo et al. [47]. In remainder of this paper, only the calculations related to energy performance characteristics will be presented in full. For other real estate characteristics, we reported only the results of some hedonic prices depending on what is indicated in the literature [48] (Table 2).

\subsection{Hedonic Price Energy Performance Index ( $\left.P_{E P I}\right)$}

The hedonic price energy performance index is calculated with $C_{\mathrm{E}}$, the annual energy costs in the first year; $i$, the capitalization rate; and $g$, the annual rate of change in energy costs:

$$
P_{\mathrm{EPI}}=\frac{C_{\mathrm{E}}}{i-g} .
$$


where:

- $\quad C_{\mathrm{E}}$ is the annual energy costs for the first year [51];

- $\quad i$ is the capitalization assay, evaluated for this market segment as $4 \%$ [52];

- $\quad g$ is the annual rate of change in energy costs, evaluated for this market segment as $1 \%$ [52].

Whereas in Italy the winter heating functions mainly using methane gas with a price of $0.091 € / \mathrm{kWh}$, summer air conditioning almost entirely is fed with electrical energy which can vary between 0.18 to $0.40 € / \mathrm{kWh}$, according to the type of electricity market used. With these assumptions, the average annual cost of energy required to guarantee comfort inside the building during both Summer and Winter can be assumed to be about $0.15 € / \mathrm{kWh}$. The annual cost of consumed energy $\left(\mathrm{C}_{\mathrm{E}}\right)$ can thus be determined in the following way:

$$
\begin{aligned}
& C^{A}{ }_{E}=0.15\left(\frac{€}{\mathrm{kWh}} \cdot \mathrm{a}\right) \times 85.00\left(\mathrm{~m}^{2}\right)=12.75 \frac{€}{\mathrm{kWh}} \cdot \mathrm{m}^{2} \mathrm{a}, \\
& C^{B}{ }_{E}=0.15\left(\frac{€}{\mathrm{kWh}} \cdot \mathrm{a}\right) \times 118.00\left(\mathrm{~m}^{2}\right)=17.70 \frac{€}{\mathrm{kWh}} \cdot \mathrm{m}^{2} \mathrm{a}, \\
& C^{C}{ }_{\mathrm{E}}=0.15\left(\frac{€}{\mathrm{kWh}} \cdot \mathrm{a}\right) \times 105.00\left(\mathrm{~m}^{2}\right)=15.75 \frac{€}{\mathrm{kWh}} \cdot \mathrm{m}^{2} \mathrm{a},
\end{aligned}
$$

The hedonic price of the characteristic energy performance is equal to:

$$
\begin{aligned}
& P_{E P I}^{\mathrm{A}}=\frac{12.75}{0.04-0.01}=425.00 € / \mathrm{kWh} \cdot \mathrm{m}^{2} \mathrm{a}, \\
& P_{\mathrm{EPI}}^{\mathrm{B}}=\frac{17.70}{0.04-0.01}=590.00 € / \mathrm{kWh} \cdot \mathrm{m}^{2} \mathrm{a}, \\
& P_{E P I}^{\mathrm{C}}=\frac{15.75}{0.04-0.01}=525.00 € / \mathrm{kWh} \cdot \mathrm{m}^{2} \mathrm{a} .
\end{aligned}
$$

\subsection{Hedonic Price Carbon Dioxide Emission $\left(P_{C D E}\right)$}

The carbon dioxide emission is calculated considering the annual cost of building emissions $C_{\mathrm{CO}_{2}}$, calculated according to the average price of a carbon credit, capitalizing on the difference between the $i$ and $g$ rates. The annual rate of the cost of carbon dioxide emissions variation rate is:

$$
P_{\mathrm{CDE}}=\frac{C_{\mathrm{CO}_{2}}}{i-g}
$$

The average price of a carbon credit (or permit or emission quota), traded in the market for carbon credits, is appraised as equal to $15.00 € / \mathrm{tCO}_{2}$ in order to determine the hedonic price of the characteristic energy performance related to $\mathrm{CO}_{2}$ emissions

$$
\begin{aligned}
& \mathrm{CO}_{2 \mathrm{~A}}=0.015\left(\frac{€}{\mathrm{kgCO}} \cdot \mathrm{a}\right) \cdot 85.00\left(\mathrm{~m}^{2}\right)=1.27 € / \mathrm{kgCO}_{2} \cdot \mathrm{m}^{2} \mathrm{a} \\
& \mathrm{CO}_{2 \mathrm{~B}}=0.015\left(\frac{€}{\mathrm{kgCO}_{2}} \cdot \mathrm{a}\right) \cdot 118.00\left(\mathrm{~m}^{2}\right)=1.77 € / \mathrm{kgCO}_{2} \cdot \mathrm{m}^{2} \mathrm{a}, \\
& \mathrm{CO}_{2 \mathrm{C}}=0.015\left(\frac{€}{\mathrm{kgCO}} \cdot \mathrm{a}\right) \cdot 105.00\left(\mathrm{~m}^{2}\right)=1.58 \frac{€}{\mathrm{kgCO}} \cdot \mathrm{m}^{2} \mathrm{a}
\end{aligned}
$$


The hedonic price of the carbon dioxide emission is equal to:

$$
\begin{aligned}
& P_{\mathrm{CDE}}^{\mathrm{A}}=\frac{1.27}{0.04-0.01}=42.33 \frac{€}{\mathrm{kgCO}} \cdot \mathrm{m}^{2} \mathrm{a}, \\
& P_{\mathrm{CDE}}^{\mathrm{B}}=\frac{1.77}{0.04-0.01}=59.00 \frac{€}{\mathrm{kgCO}} \cdot \mathrm{m}^{2} \mathrm{a}, \\
& P_{\mathrm{CDE}}^{\mathrm{C}}=\frac{1.58}{0.04-0.01}=52.70 \frac{€}{\mathrm{kgCO}} \cdot \mathrm{m}^{2} \mathrm{a} .
\end{aligned}
$$

\subsection{Sales Adjustment Grid}

The sales adjustment grid has been built according to the corrective factors indicated in Salvo et al. $[47,48]$. Table 3 reports the different features' hedonic prices.

To take account of duplication in the analysis of hedonic prices, we proceed to calculate the coefficient $r$. The $r_{\mathrm{j}}$ coefficient is calculated using the formula:

$$
\begin{gathered}
r_{\mathrm{A}}=\frac{S U R_{\text {Subject }}-S U R_{A}}{S U R_{A}}=\frac{m q 80.00-m q 85.00}{m q 85.00}=-0.059, \\
r_{\mathrm{B}}=\frac{S U R_{\text {Subject }}-S U R_{B}}{S U R_{B}}=\frac{80.00-m q 118.00}{m q 118.00}=-0.322, \\
r_{C}=\frac{S U R_{\text {Subject }}-S U R_{C}}{S U R_{C}}=\frac{m q 80.00-m q 105.00}{m q 105.00}=-0.238 .
\end{gathered}
$$

\begin{tabular}{|c|c|c|c|}
\hline Hedonic Prices & Comparable A & Comparable B & Comparable C \\
\hline $\mathrm{SUR} € / \mathrm{mq}$ & $1,870.59$ & $1,457.63$ & $1,571.43$ \\
\hline RES $€ /$ No. & $6,666.67$ & $6,666.67$ & $6,666.67$ \\
\hline MAI $€ /$ point & $10,000.00$ & $10,000.00$ & $10,000.00$ \\
\hline FLO $€ /$ level & $4,770.00$ & $5,160.00$ & $4,950.00$ \\
\hline $\mathrm{EPI} € / \mathrm{kWh} / \mathrm{m}^{2} \cdot \mathrm{a}$ & 425.00 & 590.00 & 525.00 \\
\hline $\mathrm{CDE} \mathrm{kgCO}_{2} / \mathrm{m}^{2} \cdot \mathrm{a}$ & 42.33 & 59.00 & 52.70 \\
\hline$r_{j}$ & -0.06 & -0.32 & -0.24 \\
\hline
\end{tabular}

The $r_{j}$ coefficients are significant in the hedonic price table (Table 2).

In the sales adjustment grid, every single adjustment is made explicit; the last record reports the correct prices (Table 4). It is possible to see the convergence of corrected prices, calculated using the corrective factor $r_{j}$. Table 2 reports the different features' hedonic prices.

Table 2. Hedonic Price Table.

Table 3. Sales Adjustment Grid.

\begin{tabular}{ccc}
\hline $\begin{array}{c}\text { Sale Price and Real } \\
\text { Estate Features }\end{array}$ & A & B \\
\hline $\begin{array}{c}\text { Sale Price } \\
\text { Feature }\end{array}$ & $P_{A} \cdot\left(x_{0 i}-x_{i \mathrm{~A}} \cdot\left(1+r_{\mathrm{A}}\right)\right)$ & $P_{\mathrm{B}}$ \\
$\cdots \cdots$ & $p_{i \mathrm{~B}} \cdot\left(x_{0 \mathrm{i}}-x_{i \mathrm{~B}} \cdot\left(1+r_{\mathrm{B}}\right)\right)$ \\
Correct Price & $P_{\mathrm{cA}}=P_{\mathrm{A}}+\sum_{i=1}^{n} p_{\mathrm{A}} \cdot\left(x_{0 \mathrm{i}}-x_{i \mathrm{~A}} \cdot\left(1+r_{\mathrm{A}}\right)\right)$ & $P_{c \mathrm{~B}}=P_{\mathrm{B}}+\sum_{i=1}^{n} p_{\mathrm{B}} \cdot\left(x_{0 \mathrm{i}}-x_{i \mathrm{~B}} \cdot\left(1+r_{\mathrm{B}}\right)\right)$ \\
\hline
\end{tabular}


Table 4. The case study Sales Adjustment Grid (€).

\begin{tabular}{|c|c|c|c|}
\hline Sale Price and Real Estate Feature & Comparable A & Comparable B & Comparable C \\
\hline Sale Price (SPR) & $159,000.00$ & $172,000.00$ & $165,000.00$ \\
\hline Surface (SUR) & $1,870.59 \times[(80.00-85.00)]=-9,352.95$ & $1,457.63 \times[(80.00-118.00)]=-55,389.83$ & $1,571.43 \times[(80.00-105.00)]=-39,285.72$ \\
\hline Restrooms (RES) & $6,666.67 \times[2.00-2.00 \times(1-0.059)]=784.31$ & $6,666.67 \times[2.00-1.00 \times(1-0.322)]=-4,519.77$ & $6,666.67 \times[2.00-1.00 \times(1-0.238)]=-5,079.36$ \\
\hline Maintenance (MAI) & $10,000 \times[4.00-(2.00 \times(1-0.059))]=21,176.47$ & $10,000 \times[4.00-(4.00 \times(1-0.322))]=12,881.35$ & $10,000 \times[4.00-(2.00 \times(1-0.238))]=24,761.90$ \\
\hline Floor level (FLO) & $4,770.00 \times[3.00-4.00 \times(1-0.059)]=-3,647.65$ & $5,160.00 \times[3.00-6.00 \times(1-0.322)]=-5,509.83$ & $4,950.00 \times[3.00-5.00 \times(1-0.238)]=-4,007.14$ \\
\hline Energy performance index (EPI) & $425.00 \times[265.00-220.00 \times(1-0.059)]=24,625.00$ & $590.00 \times[265.00-200.00 \times(1-0.322)]=76,350.00$ & $425.00 \times[265.00-218.00 \times(1-0.238)]=51,925.00$ \\
\hline Carbon dioxide emission (CDE) & $42.33 \times[65.00-54.00 \times(1-0.059)]=524.53$ & $59.00 \times[65.00-58.00 \times(1-0.322)]=1,515.00$ & $52.70 \times[65.00-75.00 \times(1-0.238)]=414.07$ \\
\hline Correct Price & $193,109.73$ & $197,326.92$ & $193,728.75$ \\
\hline
\end{tabular}




\subsection{Reconciliation}

The most probable market value of the subject is equal to the arithmetic average of the corrected prices:

$$
V=\frac{€(193,109.73+197,326.92+193,728.75)}{3}=€ 194,721.80 .
$$

With the sales adjustment grid of every single feature you get the effect of the real estate feature on the market value. If we proceed to quantify the relative contribution of each property characteristic to the final value, we obtain:

Table 5 shows that the characteristic Energy Performance Index (EPI) is one of the different characteristics from the surface that more than any other $(26 \%)$ contributes to the formation of the market value. The feature ' $\mathrm{CO}_{2}$ emissions' has not been recognized yet by the prospective buyer as like an important factor of energy efficiency; in fact it has a very low relative weight $(0.4 \%)$.

Table 5. Performance index.

\begin{tabular}{cc}
\hline Real Estate Feature & Performance Index (\%) \\
\hline SUR & 18 \\
RES & 1.5 \\
MAI & 10 \\
FLO & 2.3 \\
EPI & 26 \\
CDE & 0.4 \\
\hline
\end{tabular}

The MCA results and, in particular, the convergence of fixed prices obtained in the evaluation table show that it is crucial in the appraisal of the most probable value to consider the characteristics of the market value of a property, taking into account its environmental value. Indeed, it is essential not to overlook the characteristic 'energy performance' in the process of the formation of value, given the role that it plays in the price formation process.

\section{Conclusions}

This study addressed the issue of the energy performance of buildings, contextualizing it in a methodological proposal for appraising the contribution that it provides to the formation of real estate prices. The proposed methodology can be applied in Europe since the energy performance parameters (energy performance index and $\mathrm{CO}_{2}$ emissions) are present in the energy certification documents of the buildings of the most important European countries including Spain, France, Austria, Belgium, Ireland, the United Kingdom, and Germany.

The reasons for the close relationship between energy performance and value of the property are to be related to the attention paid to property management budgets, which are strongly influenced by the energy consumption costs. The proposed methodology utility is due to the application of the MCA, which allows you to achieve reliable results in the property market value in market conditions characterized by a small number of transactions. The appraisal methodology gives other methods that are able to quantify the contribution of the inductive approach component of the energy performance of a building, such as the multiple regression models. These approaches, however, require a large number of trades, knowledge of statistical methods, and the ability to interpret the results obtained. Although the 'green economy' has grown significantly in many areas, there is still little empirical evidence to show the relationship between real estate prices and their sustainability characteristics, in spite of the economic and environmental benefits that are assured.

The proposed methodological approach is deductive and, for the simplicity of application, is well suited to be used by the valuers. This study arises as a means for the dissemination of an 
international appraisal methodology that considers the energy certification characteristic of buildings not insignificant.

The importance of including the energy certification of buildings in real estate appraisals may in turn be a stimulus for an improvement in energy efficiency in housing and an improvement in the environment in general. The proposed methodology quantifies the contribution of energy efficiency to the market value of the building so that the return linked to more efficient buildings is regarded as a long-term investment, and, if so perceived, it will produce a further boost to the growth of the real estate market for buildings with low environmental impact.

Author Contributions: This paper is to be attributed in equal parts to the four authors.

Conflicts of Interest: The authors declare no conflict of interest.

\section{References}

1. European Commission (EC). Directive 2010/31/EU of the European Parliament and of the Council (Recast); EC: Brussels, Belgium, 2010.

2. International Energy Agency (IEA). $\mathrm{CO}_{2}$ Emissions from Fuel Combustion-Highlights; International Energy Agency: Paris, France, 2013.

3. Banfi, S.; Farsi, M.; Filippini, M.; Jakob, M. Willingness to pay for energy saving measures in residential buildings. Energy Econ. 2008, 30, 503-516. [CrossRef]

4. Brounen, D.; Kok, N. On the economics of energy labels in the housing market. J. Environ. Econ. Manag. 2011, 62, 166-179. [CrossRef]

5. Cajias, M.; Piazolo, D. Green performs better: Energy efficiency and financial return on buildings. J. Corp. Real Estate 2013, 15, 53-72. [CrossRef]

6. Cerin, P.; Hassel, L.; Semenova, N. Energy Performance and Housing Prices. Sustain. Dev. 2014, 22, 404-419. [CrossRef]

7. Department of Energy and Climate Change. An Investigation of the Effect of EPC Ratings on House Prices; Department of Energy and Climate Change: London, UK, 2013.

8. European Commission (EC). Energy Performance Certificates In buildings and Their Impact on Transaction Prices and Rents in Selected EU Countries; EC: Brussels, Belgium, 2013.

9. Hyland, M.; Lyons, R.C.; Lyons, S. The value of domestic building energy efficiency-Evidence from Ireland. Energy Econ. 2013, 40, 943-952. [CrossRef]

10. Popescu, D.; Bienert, S.; Schützenhofer, C.; Boazu, R. Impact of energy efficiency measures on the economic value of buildings. Appl. Energy 2012, 89, 454-463. [CrossRef]

11. Amecke, H. The impact of energy performance certificates: A survey of German homeowners. Energy Policy 2012, 46, 4-14. [CrossRef]

12. Murphy, L. The Influence of the Energy Performance Certificate: The Dutch Case. Energy Policy 2014, 67, 664-672. [CrossRef]

13. Allcot, H.; Greenstone, M. Is there an Energy Efficiency Gap? J. Econ. Perspect. 2012, 26, 3-28. [CrossRef]

14. European Commission (EC). Financial Support for Energy Efficiency in Buildings; EC: Brussels, Belgium, 2013.

15. Gillingham, K.; Newell, R.; Palmer, K. Energy Efficiency Economics and Policy. Annu. Rev. Resour. Econ. 2009, 1, 597-620. [CrossRef]

16. Gillingham, K.; Harding, M.; Rapson, D. Split Incentives in Residential Energy Consumption. Energy J. 2012, 33, 37-62. [CrossRef]

17. Chegut, A.; Eichholtz, P.; Kok, N. The value of green buildings: New evidence from the United Kingdom. In Proceedings of the International AREUEA Meeting, Rotterdam, The Netherlands, 17-19 June 2010.

18. Eichholtz, P.; Kok, N.; Quigley, J.M. Doing Well by Doing Good: Green Office Buildings. Am. Econ. Rev. 2010, 100, 2494-2511. [CrossRef]

19. Fuerst, F.; McAllister, P. Green Noise or Green Value? Measuring the Effects of Environmental Certification on Office Values. Real Estate Econ. 2011, 39, 45-69.

20. Miller, E.; Buys, L. Retrofitting commercial office buildings for sustainability: Tenants' perspectives. J. Prop. Invest. Financ. 2008, 26, 552-561. [CrossRef] 
21. Pivo, G.; Fisher, J. Income, Value and Returns on Socially Responsible Office Properties. J. Real Estate Res. 2010, 32, 243-269.

22. Wiley, J.A.; Benefield, J.D.; Johnson, K.H. Green design and the market for commercial office space. J. Real Estate Financ. Econ. 2008, 41, 228-243. [CrossRef]

23. Deng, Y.; Li, Z.; Quigley, J.M. Economic Returns to Energy-Efficiency Investments in the Housing Market: Evidence from Singapore. Reg. Sci. Urban Econ. 2011, 42, 506-515. [CrossRef]

24. Högberg, L. The impact of energy performance on single-family home selling prices in Sweden. J. Eur. Real Estate Res. 2013, 6, 242-261. [CrossRef]

25. Kahn, M.E.; Kok, N. The Value of Green Labels in the Californian Housing Market; Working Paper; U.S. Green Building Council: Washington, DC, USA, 2012.

26. Jensen, O.M.; Hansen, A.R.; Kragh, J. Market response to the public display of energy performance rating at property sales. Energy Policy 2016, 93, 229-235. [CrossRef]

27. Fuerst, F.; McAllister, P. The impact of Energy Performance Certificates on the rental and capital values of commercial property assets. Energy Policy 2011, 39, 6608-6614. [CrossRef]

28. Fuerst, F.; McAllister, P.; Nanda, A.; Wyatt, P. Energy performance ratings and house prices in Wales: An empirical study. Energy Policy 2016, 92, 20-33. [CrossRef]

29. Walls, M.; Palmer, K.; Gerarden, T. Is Energy Efficiency Capitalized into Home Prices? Evidence from Three US Cities; Resources for the Future Discussion Paper; Resources for the Future: Washington, DC, USA, 2013.

30. Yoshida, J.; Sugiura, A. Which 'Greenness' is Valued? Evidence from Green Condominiums in Tokyo; Munich Personal RePEc Archive: Munich, Germany, 2010.

31. Fuerst, F.; McAllister, P. New evidence on the green building rent and price premium. In Proceedings of the Annual Meeting of the American Real Estate Society, Monterey, CA, USA, 1-4 April 2009.

32. Eichholtz, P.; Kok, N.; Quigley, J.M. Why Do Companies Rent Green? Real Property and Corporate Social Responsibility; Berkeley Program on Housing and Urban Policy Working Paper W09-004; University of California: Berkeley, CA, USA, 2009.

33. Morano, P.; Tajani, F. Bare ownership evaluation. Hedonic price model vs. artificial neural network. Int. J. Bus. Intell. Data Min. 2013, 8, 340-362.

34. Manganelli, B.; De Paola, P.; Del Giudice, V. Linear programming in a multi-criteria model for real estate appraisal. Lect. Notes Comput. Sci. 2016, 9786, 182-192.

35. Anderson, S.T.; Newell, R.G. Information Programs for Technology Adoption: The Case of Energy-Efficiency Audits. Resour. Energy Econ. 2004, 26, 27-50. [CrossRef]

36. Chao, M.; Parker, G. Recognition of Energy Costs and Energy Performance in Commercial Property Valuation; New York State Energy Research and Development Authority: New York, NY, USA, 2000.

37. Finlay, J. Valuation Techniques of High-Performance Real Estate. UCLA Real Estate Market Analysis, 23 August 2010.

38. Finlay, J. The Resource Appraisal: Due Diligence Reporting for Energy/Resource Performance Retrofit Financing. In Proceedings of the Strengthening the Green Foundation: Research and Policy Directions for Development and Finance, New Orleans, LA, USA, 10 March 2011.

39. Miller, N.G.; Pogue, D.; Gough, Q.D.; Davis, S.M. Green Buildings and Productivity. J. Sustain. Real Estate 2009, 1, 65-90.

40. Fuerst, F.; McAllister, P. An Investigation of the Effect of Eco-Labeling on Office Occupancy Rates. J. Sustain. Real Estate 2009, 1, 49-64.

41. Dermisi, S. Effect of LEED Ratings and Levels on Office Property Assessed and Market Values. J. Sustain. Real Estate 2009, 1, 23-47.

42. Dermisi, S.; McDonald, J. Effect of 'Green' (LEED and Energy Star) Designation on Prices/SF and Transaction Frequency: The Case of the Chicago Office Market. J. Real Estate Portf. Manag. 2011, 17, 39-52.

43. G8 Information Centre. In Proceedings of the Leaders' Declaration: G7 Summit, Schloss Elmau, Germany, 8 June 2015.

44. European Commission (EC). Directive 2012/27/EU of the European Parliament and of the Council of 25 October 2012 on energy efficiency, amending Directives 2009/125/EC and 2010/30/EU and repealing Directives 2004/8/EC and 2006/32/EC; EC: Brussels, Belgium, 2012.

45. International Valuation Standards Council (IVSC). International Valuation Standards 2011; IVSC: London, UK, 2011. 
46. Colwell, P.; Cannaday, R.E.; Wu, C. The Analytical Foundations of Adjustment Grid Method. J. Am. Real Estate Urban Econ. Assoc. 1983, 11, 11-29. [CrossRef]

47. Salvo, F.; Simonotti, M.; Ciuna, M.; De Ruggiero, M. Measurements of rationality for a scientific approach to the Market Oriented Methods. J. Real Estate Lit. 2016, 24, 403-427.

48. Salvo, F.; De Ruggiero, M. Market Comparison Approach between tradition and innovation. A simplifying approach. Aestimum 2013, 62, 585-594.

49. Manganelli, B. Real Estate Investing: Market Analysis, Valuation Techniques, and Risk Management; Springer International Publishing: Cham (ZG), Switzerland, 2015; pp. 97-135.

50. European Commission (EC). Directive 2003/87/EC of the European Parliament and of the Council of 13 October 2003 Establishing a Scheme for Greenhouse Gas Emission Allowance Trading Within the Community and Amending Council Directive 96/61/EC; EC: Brussels, Belgium, 2003.

51. Authority for Electricity and Gas and the Water System. Available online: http://www.autorita.energia.it (accessed 10 January 2017).

52. Orefice, M. Estimo; UTET: Torino, Italy, 2000; Volumes 1-4.

(c) 2017 by the authors. Licensee MDPI, Basel, Switzerland. This article is an open access article distributed under the terms and conditions of the Creative Commons Attribution (CC BY) license (http:/ / creativecommons.org/licenses/by/4.0/). 